\title{
Association between peripheral muscle strength, exercise performance, and physical activity in daily life in patients with Chronic Obstructive Pulmonary Disease
}

\author{
Anne-Kathrin Rausch-Osthoff ${ }^{1,2,4^{*}}$, Malcolm Kohler ${ }^{1,3}$, Noriane A Sievi ${ }^{1}$, Christian F Clarenbach ${ }^{1}$ \\ and Arnoldus JR van Gestel ${ }^{1,2}$
}

\begin{abstract}
Background: Resistance training of peripheral muscles has been recommended in order to increase muscle strength in patients with Chronic Obstructive Pulmonary Disease (COPD). However, whether peripheral muscle strength is associated with exercise performance (EP) and physical activity in daily life (PADL) in these patients needs to be investigated.

The aim of this study is to evaluate whether strength of the quadriceps muscle (QS) is associated with EP and daily PADL in patients with COPD.

Methods: We studied patients with COPD (GOLD A-D) and measured maximal isometric strength of the left QS. PADL was measured for 7 days with a SenseWear-Pro ${ }^{\circledR}$ accelerometer. EP was quantified by the 6-minute walk distance (6MWD), the number of stands in the Sit-to-Stand Test (STST), and the handgrip-strength. Univariate and multivariate analyses were used to examine possible associations between QS, PADL and EP.

Results: In 27 patients with COPD with a mean (SD) FEV 1 of 37.6 (17.6)\% predicted, QS was associated with 6MWD, STST, and handgrip-strength but not with PADL. Multiple linear regression analyses showed that QS was independently associated with the $6 \mathrm{MWD}(\beta=0.42,95 \% \mathrm{Cl} 0.09$ to $0.84, p=0.019)$, STST ( $\beta=0.50,95 \% \mathrm{Cl} 0.11$ to $0.86, p=0.014)$ and with handgrip-strength $(\beta=0.45,95 \% \mathrm{Cl} 0.05$ to $0.84, p=0.038$.

Conclusions: Peripheral muscle strength may be associated with exercise performance but not with physical activity in daily life. This may be due to the fact that EP tests evaluate patients' true abilities while PADL accelerometers may not.
\end{abstract}

Keywords: Accelerometer, Handgrip-strength, Quadriceps strength, Six-minute-walk-distance, Sit-to-stand-test

\section{Background}

Physical inactivity in daily life is a prominent feature in patients with Chronic Obstructive Pulmonary Disease (COPD) [1-4] and the amount of physical activity in daily life (PADL) gradually declines with the severity of disease [4-6]. Several studies have demonstrated that the level of PADL is associated with the number of

\footnotetext{
* Correspondence: anne-kathrin.rauschosthoff@zhaw.ch

'Pulmonary Division, University Hospital of Zurich, Zurich, Switzerland ${ }^{2}$ Department of Physiotherapy, Zurich University of Applied Sciences, Winterthur, Switzerland

Full list of author information is available at the end of the article
}

hospitalizations [7-9] and is known as the strongest predictor of all-cause mortality $[7,10]$ in patients with COPD. As a result, both the American Thoracic Society and the European Respiratory Society [11] stressed the fact that long-term self-management and adherence to exercise at home should be the primary goals of pulmonary rehabilitation programs (PR).

One of the extrapulmonary manifestations of COPD is skeletal muscle dysfunction [12-15] and therefore resistance training of peripheral muscles has been strongly recommended during pulmonary rehabilitation (PR) $[16,17]$. As there is compelling evidence highlighting the role of

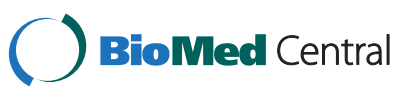

(c) 2014 Rausch-Osthoff et al.; licensee BioMed Central Ltd. This is an Open Access article distributed under the terms of the Creative Commons Attribution License (http://creativecommons.org/licenses/by/4.0), which permits unrestricted use, distribution, and reproduction in any medium, provided the original work is properly credited. The Creative Commons Public Domain Dedication waiver (http://creativecommons.org/publicdomain/zero/1.0/) applies to the data made available in this article, unless otherwise stated. 
muscular strength in exercise performance (EP) in patients with COPD $[13,18-22]$, it seems reasonable to assume that enhanced peripheral muscle strength subsequently leads to improvements in performing daily tasks and participating in daily life activities. However, it is currently unclear whether peripheral muscle strength is associated with daily physical activity levels (PAL) in patients with COPD. The methods used to assess PADL in previous studies were very different [8,23-30]. Only very few data are available from studies assessing PADL objectively with a multi-dimensional accelerometer. Furthermore, the results of these studies were conflicting: five studies [8,23-26] demonstrated a positive association between quadriceps strength (QS) and PADL whereas four studies [27-30] did not.

Investigating the role of peripheral muscle strength and its contribution to exercise tolerance may be important for understanding the pathophysiology of exercise limitation and reduced PADL in patients with COPD and may help to define the best therapeutic approach in these patients. Therefore, the purpose of the present study was to examine the relationship between QS and EP (reflected by the 6-minute walk distance (6MWD), the number of stands in the Sit-to-Stand Test (STST), handgrip-strength) and PADL as assessed by a multi-dimensional accelerometer (the SenseWear Pro ${ }^{\circ}$ armband) in patients with COPD.

\section{Methods}

\section{Study design}

A cross-sectional study in patients with COPD (GOLDclassification A-D) was performed.

Patients with COPD referred to the Pulmonary Division, University Hospital of Zurich, Switzerland between March and September 2012 were considered for participation in the study. The inclusion criteria for patients were: male and female subjects aged 40-75 years and confirmed COPD according to GOLD-guidelines [31]. The participants were included in a convenience sample. The study was approved by the Research Ethics Committee of the University Hospital of Zurich, Switzerland (KEK-ZH-NR: 2011-0106/1) and written informed consent was obtained from all patients.

\section{Sample size calculation}

The sample size calculation was based on the results reported by Mador and colleagues [24].

We calculated that the minimum sample size needed to detect a significant association between QS and PADL with $80 \%$ power, a significance level of .05 and a hypothetical drop-out-rate due to technical problems of $25 \%$, would be 23 subjects.

\section{Measurements \\ Pulmonary function}

Spirometry, whole-body plethysmography and diffusion capacity measurements were performed according to the American Thoracic Society (ATS) and the European Respiratory Society (ERS) guidelines with a commercially available system $[32,33]$.

\section{Six-minute-walk-test (6MWT)}

Patients performed the $6 \mathrm{MWT}$ following pulmonary function testing. The 6MWT was conducted in accordance with the ATS guidelines [34]. None of the patients used a walking aid in daily life or during the test. The 6MWT was performed on a 30-meter indoor track by an experienced investigator using standardized encouragement strategy [35]. Subjects were allowed to rest if needed. Measurements of $\mathrm{SpO} 2$ were performed using a finger pulse oximeter (TuffSat ${ }^{\mathrm{Tm}}$, DatexOhmeda, USA, and PureLight ${ }^{\odot}$ 8000, Nonin Medical Inc., Sweden). SpO2, dyspnoea and leg fatigue [36] were assessed after a resting period of 5 minutes immediately after the test.

\section{Sit-to-stand-test}

The STST was performed in a distraction-protected environment. A standard chair (46 cm height) without arm supports was used. Subjects were asked to stand up from and sitting down on the chair with arms stationary on the hips, repeating the procedure as many times as possible within 1 minute at a patient-defined pace. The patients had to stand in full extension (knee and hip extension) and sitting in a position with their knees at $90^{\circ}$ flexion. The number of completed repetitions was counted [37].

\section{Handgrip-strength}

Handgrip-strength of the dominant hand was measured with a dynamometer (Hand-Dynamometer Bremshey; Accell Fitness, Almere, Netherlands) as described elsewhere [38].

\section{Quadriceps strength}

Isometric strength of the left quadriceps muscle group was measured during maximum voluntary contraction (QMVC) with the hips and knees in $90^{\circ}$ flexion. QMVC was defined as the highest mean strength that could be sustained over $3 \mathrm{~s}$ and expressed in Newton-meters $(\mathrm{Nm})$.

Strength was measured with a strap looped around the left leg just proximal to the ankle and connected to a strain gauge. The strain gauge was connected to the Interface series SM S-Type Load Cell (U.S. \& Metric) and the Nexus-10 ${ }^{\mathrm{Tm}}$ device (TMS International BV, Netherlands). All subjects were studied while seated in an adjustable straight-backed chair. Three maximum voluntary contractions were recorded for each patient. The average of the three scores was used for further 
analysis. After each test the patients were able to rest for a period of two minutes.

\section{Physical activity in daily life}

Daily Physical Activity was measured by a multisensor accelerometer (SenseWear Pro $^{\circ}$ armband; BodyMedia, Inc., Pittsburgh, PADL, USA), which was worn on the upper right arm. The device estimates energy expenditure (EE) using measurements from a biaxial accelerometer and sensors that quantify galvanic skin response, heat flux and skin temperature. The biaxial accelerometer records the number of steps per day and the duration of PADL [18]. The number of steps per day, metabolic equivalent (MET), total energy expenditure (TEE), and PAL were used in the present study. PAL was calculated using TEE and sleep expenditure as a surrogate for resting energy expenditure (REE) $(\mathrm{PAL}=\mathrm{TEE} / \mathrm{REE})$. The patients were instructed to wear the accelerometer continuously during 7 consecutive days, except when bathing or showering. The SenseWear $\mathrm{Pro}^{\circ}$ armband was validated to accurately measure PADL and quantify EE in patients with COPD [39-41].

\section{Statistics}

A statistical software package was used for all calculations (SPSS ${ }^{\circ}$ for Windows, Version 20.0, SPSS Inc., Chicago, IL, USA). Descriptive data for continuous variables are expressed as mean, standard deviation and percentages for frequencies. Variables were tested for parametric distribution by applying the Shapiro-Wilk Test (null hypothesis rejection set at $\mathrm{p}<0.25$ ). Univariate regression was performed to evaluate a possible association between QS and measures reflecting PADL derived from accelerometry, $6 \mathrm{MWD}$, the number of stands during the STST, and handgrip-strength. The multivariate analysis was performed to analyse if QS is independently associated with these measures reflecting PADL and EP. The multivariate analysis included measures of PADL that showed significant associations in the univariate regression analysis, Forced Expiratory Volume in 1 second $\left(\mathrm{FEV}_{1}\right)$ and age. $\mathrm{A} \mathrm{p}<0.05$ was considered to indicate statistical significance.

\section{Results}

Figure 1 shows the study profile. Twenty-seven patients (thirteen females) with COPD and an average age of $62 \pm$ 5 years agreed to take part and were included in the study. Anthropometrical characteristics and data reflecting pulmonary function, EP and PADL are presented in Table 1. Patients reported the following comorbidities: diabetes mellitus, osteoporosis, hypertension, depression, arthritis, and peripheral arterial disease. Five of participating subjects declared to be active smokers. The majority of patients $(74.1 \%)$ were "at high risk and with high symptom burden” (GOLD D).

\section{Physical activity}

In four of the 27 patients PADL data were unavailable due to technical problems. Therefore, the analysis of PADL data included 23 patients. The mean PAL of the patients was 1.44 (0.16) (Table 1); $41 \%$ of the patients had an extremely inactive lifestyle $(\mathrm{PAL}<1.4), 55 \%$ had a sedentary lifestyle (PAL 1.40-1.69) and $4 \%$ were classified as moderate to vigorously active ( $\mathrm{PAL} \geq 1.70$ ). Mean total energy expenditure (TEEACC) estimated by accelerometry was $2222(467) \mathrm{kcal} /$ day.

\section{Relationship between quadriceps strength, exercise performance and physical activity}

There was a statistically significant positive association between QS and the 6MWD (Figure 2), the number of stands during the STST, and handgrip-strength, but not with PADL as assessed by the SenseWear Pro ${ }^{\circ}$ armband (Table 2).

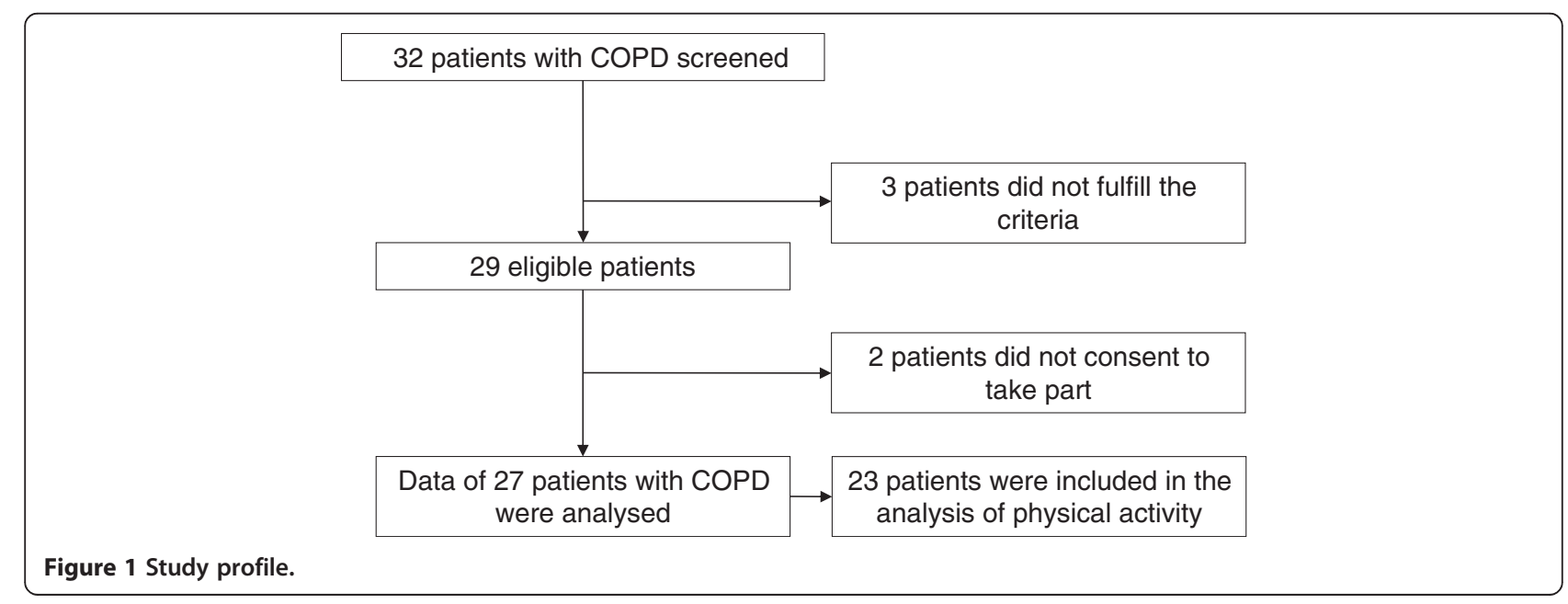


Table 1 Anthropometrical characteristics and pulmonary function, EP and PADL data of the study group

\begin{tabular}{|c|c|}
\hline Variable & \\
\hline \multicolumn{2}{|l|}{ Anthropomertrics } \\
\hline Subjects (n) & 27 \\
\hline Female/male & $11 / 16$ \\
\hline Age (years) & $62.3(5.7)$ \\
\hline $\mathrm{BMI}(\mathrm{kg} / \mathrm{m} 2)$ & $24.5(5.8)$ \\
\hline \multicolumn{2}{|l|}{ GOLD-Classification } \\
\hline A & $3.7 \%$ \\
\hline B & $18.5 \%$ \\
\hline C & $3.7 \%$ \\
\hline $\mathrm{D}$ & $74.1 \%$ \\
\hline \multicolumn{2}{|l|}{ Pulmonary function } \\
\hline $\mathrm{FEV}_{1}(\mathrm{I})$ & $1.1(0.6)$ \\
\hline $\mathrm{FEV}_{1}$ (\% predicted) & $37.6(17.6)$ \\
\hline $\mathrm{FEV}_{1} / \mathrm{FVC}$ (ratio) & $0.40(0.14)$ \\
\hline TLC (\% predicted) & $112.6(25.4)$ \\
\hline $\mathrm{RV} / \mathrm{TLC}$ & $56.8(10.7)$ \\
\hline $\mathrm{PaO}_{2}(\mathrm{kPa})$ & $9.5(1.9)$ \\
\hline $\mathrm{PaCO}_{2}(\mathrm{kPa})$ & $5.1(0.5)$ \\
\hline \multicolumn{2}{|l|}{ Exercise performance } \\
\hline $6 \mathrm{MWD}(\mathrm{m})$ & $390(103)$ \\
\hline Sit-to-Stand Test (n) & $20(7)$ \\
\hline Handgrip Test (kg) & $33.7(10.3)$ \\
\hline Quadriceps strength (Nm) & $14.5(5.2)$ \\
\hline \multicolumn{2}{|c|}{ Daily physical activity by accelerometry } \\
\hline PAL (ratio) & $1.44(0.16)$ \\
\hline MET (kcal/h/kg) & $30.3(4.7)$ \\
\hline TEEACC (kcal/day) & $2222(467)$ \\
\hline Steps/day (n) & $4097(2325)$ \\
\hline Time <3METs (min) & $1341(876)$ \\
\hline Time 3-6 METs (min) & $86(30)$ \\
\hline Time >6 METs (min) & $0(2)$ \\
\hline
\end{tabular}

Values are presented as mean (SD). $\mathrm{BMI}$, body mass index; $\mathrm{DL}_{\mathrm{CO}}$, diffusion capacity for carbon monoxide; $\mathrm{FEV}_{1}$, forced expiratory volume in one second $\mathrm{FEV}_{1} / \mathrm{FVC}$ ratio, forced expiratory volume in $1 \mathrm{sec}\left(\mathrm{FEV}_{1}\right)$ expressed as percent of FVC; MET, metabolic equivalent; PAL, physical activity level; $\mathrm{PaCO}_{2}$, partial pressure of carbon dioxide; $\mathrm{PaO}_{2}$, partial pressure of oxygen; $\mathrm{RV} / \mathrm{TLC}$, residual volume/total lung capacity ratio; TEEACC, total energy expenditure per day as assessed by accelerometry; TLC, total lung capacity.

The results of the multivariate analyses are shown in Tables 3, 4 and 5. After correction for age and $\mathrm{FEV}_{1}$, QS was found to be independently associated with the number of stands during the STST ( $\beta=0.50,95 \%$ CI 0.11 to $0.86, \mathrm{p}=0.014)$ and handgrip-strength $(\beta=0.45,95 \% \mathrm{CI}$ 0.05 to $0.84, \mathrm{p}=0.038$ ). Both $\mathrm{FEV}_{1}$ and $\mathrm{QS}$ were independently associated with the 6MWD (QS: $\beta=0.42,95 \%$ CI 0.09 to $0.84, \mathrm{p}=0.019$ ). $52.4 \%$ of the variance in 6MWD could be explained by the model (Table 3). QS

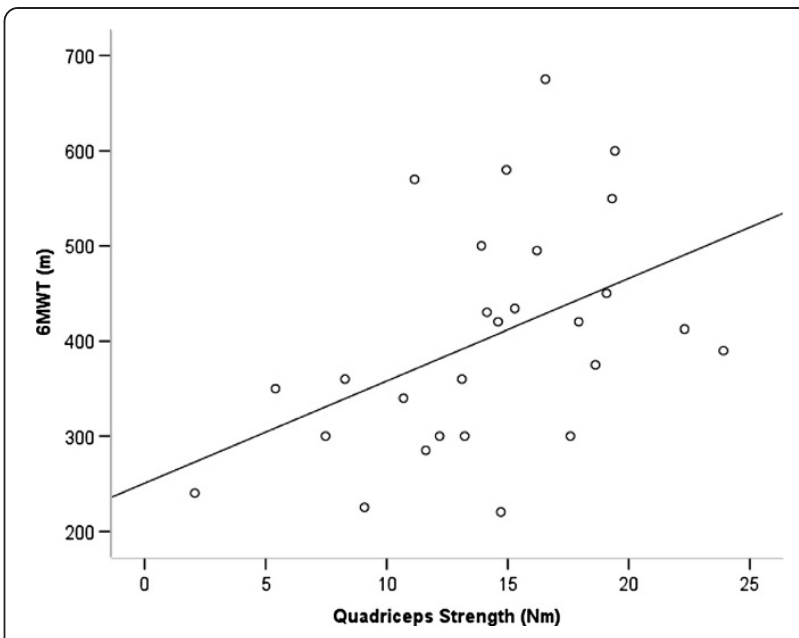

Figure 2 Scatterplot showing the relationship between quadriceps strength and the 6-minute walk distance, 6MWD $(\beta=0.45,95 \% \mathrm{Cl} 0.085$ to $0.835, \mathrm{p}=0.018)$.

explained $50.2 \%$ and $45.5 \%$ of the variance in the number of stands during the STST and handgrip-strength, respectively (Tables 4 and 5).

\section{Discussion}

In 27 patients with COPD (GOLD A-D) QS was independently associated with the $6 \mathrm{MWD}$, the number of stands in the STST, handgrip-strength but not with PADL as assessed by the SenseWear $\mathrm{Pro}^{\circ}$ armband.

It has been recognized that skeletal muscle dysfunction is a common feature in patients with COPD, and may play a significant role in morbidity and mortality [42]. Several authors $[19,43,44]$ have demonstrated that peripheral muscle weakness may be a major contributor to exercise limitation in COPD. Killian and colleagues [22] measured leg effort and dyspnoea in 97 patients with chronic airway

Table 2 Associations with quadriceps strength

\begin{tabular}{llll}
\hline Variable & Coefficient $\boldsymbol{\beta}$ & $\mathbf{9 5 \% ~ C l}$ & $\mathbf{p}$ \\
\hline Daily physical activity & & & \\
MET (kcal/24 h/kg) & 0.100 & $-0.371-0.582$ & 0.650 \\
TEEACC (kcal/day) & 0.274 & $-0.171-0.749$ & 0.206 \\
PAL & 0.092 & $-0.345-0.516$ & 0.684 \\
Steps/day (n) & -0.085 & $-0.567-0.387$ & 0.699 \\
Exercise performance & & & \\
6MWD (m) & 0.451 & $0.085-0.835$ & 0.018 \\
Sit-to-Stand test (n) & 0.502 & $0.105-0.857$ & 0.015 \\
Handgrip test (kg) & 0.455 & $0.050-0.837$ & 0.029 \\
Time < 3METs (min) & -0.055 & $-0.811-0.434$ & 0.822 \\
Time 3-6 METs (min) & 0.449 & $-0.111-1.010$ & 0.080 \\
\hline
\end{tabular}

Univariate regression is expressed as $\beta .6 \mathrm{MWD}$, 6-minute walk distance, MET, metabolic equivalent; PAL, physical activity level; TEEACC, total energy expenditure per day as assessed by accelerometry. $P<5 \%$ is significant. 
Table 3 Multiple regression analysis of predictors of the 6MWD (m)

\begin{tabular}{llllll}
\hline Model 1 & Coefficient B & Std. Error & Coefficient $\boldsymbol{\beta}$ & $\mathbf{t}$ & $\mathbf{p}$ \\
\hline Residual & 434.893 & 162.825 & & 2.67 & 0.014 \\
$\begin{array}{l}\text { Quadriceps } \\
\text { muscle } \\
\text { strength (Nm) }\end{array}$ & 10.02 & 3.96 & 0.42 & 2.53 & 0.019 \\
$\begin{array}{l}\text { FEV } 1 \\
\text { (\% predicted) }\end{array}$ & 2.29 & 1.04 & 0.371 & 2.20 & 0.038 \\
Age (years) & -4.30 & 2.56 & -0.28 & -1.68 & 0.107
\end{tabular}

6MWD, 6-minute walk distance; $\mathrm{FEV}_{1}$, forced expiratory volume in one second $(\mathrm{r} 2=0.524)$.

obstruction during maximal cycle ergometry. Indeed, patients complained more about leg discomfort than about dyspnoea after cycle ergometry. In accordance with these results, in this study we found that QS was independently associated with exercise performance (EP) as quantified by several laboratory-based tests.

International guidelines recommend exercise training to improve skeletal muscle function as an essential component of PR in patients with COPD [11,16]. However, in order to be meaningful for patients with COPD, improvements in peripheral muscle strength need to be translated into changes in PADL and participation in everyday situations. As there is compelling evidence highlighting the role of muscular strength in the EP in patients with COPD, it seems reasonable to assume that impaired muscle strength subsequently leads to difficulties in performing daily tasks and participating in daily life activities. However, we failed to demonstrate an association between QS and any measure reflecting PADL as assessed by the SenseWear $\mathrm{Pro}^{\circ}$ armband in the patients of our study.

After reviewing the literature, a total of nine studies, which investigated the association between QS and PADL in patients with COPD were found. Out of nine studies only two $[25,27]$ used a multi-sensor accelerometer to objectively quantify PADL. Five studies [8,23-26] succeeded to demonstrate an association between QS and PADL and four [27-30] failed to demonstrate such association.

Table 4 Multiple regression analysis of predictors of the number of stands (STST)

\begin{tabular}{llllll}
\hline Model 2 & Coefficient B & Std. Error & Coefficient $\boldsymbol{\beta}$ & $\mathbf{t}$ & $\mathbf{p}$ \\
\hline Residual & 14.71 & 13.19 & & 1.12 & 0.279 \\
$\begin{array}{l}\text { Quadriceps } \\
\text { muscle }\end{array}$ & 0.85 & 0.31 & 0.50 & 2.71 & 0.014 \\
$\begin{array}{l}\text { strength (Nm) } \\
\text { FEV }{ }_{1}\end{array}$ & 0.15 & 0.10 & 0.28 & 1.52 & 0.146 \\
$\begin{array}{l}\text { (\% predicted) } \\
\text { Age (years) }\end{array}$ & -0.22 & 0.19 & -0.22 & -1.19 & 0.250 \\
\hline
\end{tabular}

$\mathrm{FEV}_{1}$, forced expiratory volume in one second $(\mathrm{r} 2=0.502), \mathrm{STST}$, Sit-to-Stand Test.
Table 5 Multiple regression analysis of predictors of handgrip-strength

\begin{tabular}{llllll}
\hline Model 3 & Coefficient B & Std. Error & Coefficient $\boldsymbol{\beta}$ & $\mathbf{t}$ & $\mathbf{p}$ \\
\hline Residual & 24.13 & 18.15 & & 1.330 & 0.199 \\
$\begin{array}{l}\text { Quadriceps } \\
\text { muscle }\end{array}$ & 0.96 & 0.42 & 0.45 & 2.23 & 0.038 \\
$\begin{array}{l}\text { strength (Nm) } \\
\text { FEV }\end{array}$ & 0.07 & 0.11 & 0.13 & 0.52 & 0.517 \\
$\begin{array}{l}\text { (\% predicted) } \\
\text { Age (years) }\end{array}$ & -0.11 & 0.27 & -0.85 & -0.42 & 0.680 \\
\hline
\end{tabular}

$\mathrm{FEV}_{1}$, forced expiratory volume in one second $(\mathrm{r} 2=0.455)$.

In this study QS was independently associated with EP but not with PADL as assessed by the SenseWear Pro ${ }^{\circ}$ armband. Although the design of this study does not allow to establish a causal relationship between QS and PADL, these results need to be elucidated. In a previous research we demonstrated that EP tests do not necessarily reflect daily activities in patients with COPD accurately [45]. This may be due to the fact that EP tests evaluate patients' true abilities while PADL accelerometers may not. Differences may depend on personal factors, such as effort spent, time for leisure activities and motivation, but also external factors such as the instructions and the encouragement given to the participants during EP testing in a clinical setting [45]. This may explain the fact that QS is not associated with PADL in the patients of our study.

It should be stressed that correlations do not prove causal relationships. Interventional studies investigating the effect of PR-induced improvements in peripheral muscle strength on daily PADL allow for a more precise and meaningful examination of the association between QS and PADL. Although the main purpose of PR should be enhancing PADL [31], only few studies have investigated the impact of PR on PADL in patients with COPD. Pitta and colleagues [46] assessed PADL at baseline, after three months and at the end of a six-month multidisciplinary rehabilitation program in 29 patients with COPD. Although three months of PR improved exercise capacity and QS, these improvements did not result in patients spending more time walking in daily life. After additional three months of PR, PADL did actually increase [46]. However, it would be more powerful to analyse if PRinduced improvements in QS are associated with improvements in PADL in patients with COPD. In the only study that addressed this issue [24], PR-induced improvements in QS did not predict changes in PADL. This is in good accordance with the findings of the present study, that QS is not related to the level of PADL in patients with COPD.

\section{Limitations}

The present study has certain limitations that need to be taken into account. The number of subjects is small given the variance in data. In addition, the majority of 
the study population represents GOLD D, which may affect outcomes. We did not investigate potential exercise performance limiting factors such as hemodynamic factors, cardiac autonomic nervous system factors, and psychological factors (motivation, anxiety and depression). Neither did we control for the use of long-acting $\beta_{2}$-agonists, which may have a small effect on exercise performance and PADL. Furthermore, because cardiopulmonary exercise testing (CPET) is regarded as the gold standard assessment for evaluating exercise capacity, the tests used in this study may not reflect the true exercise capacity. It should be stressed that the results of the STST mainly reflect the performance of lower extremity muscles.

\section{Conclusions}

We conclude that quadriceps strength may be associated with exercise capacity as assessed by several laboratorybased tests such as the 6-minutes walking test, the sit-tostand test and handgrip-strength. Future well-designed interventional trials investigating the predominant role of peripheral muscle strength on daily physical activity are needed to establish the preliminary finding of the current study. However, quadriceps strength was not associated with physical activity levels in patients with COPD. This may be due to the fact that patients with COPD do not exhaust their functional abilities during daily living, as they do during laboratory-based testing.

\section{Competing interest}

None of the authors has a conflict of interest related to the content of the manuscript.

\section{Author details \\ 'Pulmonary Division, University Hospital of Zurich, Zurich, Switzerland. ${ }^{2}$ Department of Physiotherapy, Zurich University of Applied Sciences, Winterthur, Switzerland. ${ }^{3}$ Centre for Integrative Human Physiology, University of Zurich, Zurich, Switzerland. ${ }^{4}$ Zurich University of Applied Sciences, School of Health Professions, Department of Physiotherapy, Technikumstrasse 71, 8401 Winterthur, Switzerland.}

Received: 11 February 2014 Accepted: 18 June 2014 Published: 3 July 2014

\section{References}

1. Kapella MC, Larson JL, Patel MK, Covey MK, Berry JK: Subjective fatigue, influencing variables, and consequences in chronic obstructive pulmonary disease. Nurs Res 2006, 55:10-17.

2. Donaldson GC, Wilkinson TM, Hurst JR, Perera WR, Wedzicha JA: Exacerbations and time spent outdoors in chronic obstructive pulmonary disease. Am J Respir Crit Care Med 2005, 171:446-452.

3. Decramer M, Gosselink R, Troosters T, Verschueren M, Evers G: Muscle weakness is related to utilization of health care resources in COPD patients. Eur Respir 」 1997, 10:417-423.

4. Vorrink SN, Kort HS, Troosters T, Lammers JW: Level of daily physical activity in individuals with COPD compared with healthy controls. Respir Res 2011, 12:33.

5. Hartman JE, Boezen HM, de Greef MH, Bossenbroek L, ten Hacken NH: Consequences of physical inactivity in chronic obstructive pulmonary disease. Expert Rev Respir Med 2010, 4:735-745.

6. Troosters T, Sciurba F, Battaglia S, Langer D, Valluri SR, Martino L, Benzo R, Andre D, Weisman I, Decramer M: Physical inactivity in patients with
COPD, a controlled multi-center pilot-study. Respir Med 2010, 104:1005-1011.

7. Garcia-Aymerich J, Lange P, Benet M, Schnohr P, Anto JM: Regular physical activity reduces hospital admission and mortality in chronic obstructive pulmonary disease: a population based cohort study. Thorax 2006, 61:772-778.

8. Pitta F, Troosters T, Probst VS, Spruit MA, Decramer M, Gosselink R: Physical activity and hospitalization for exacerbation of COPD. Chest 2006, 129:536-544.

9. Garcia-Aymerich J, Farrero E, Felez MA, Izquierdo J, Marrades RM, Anto JM: Risk factors of readmission to hospital for a COPD exacerbation: a prospective study. Thorax 2003, 58:100-105.

10. Waschki B, Kirsten A, Holz O, Müller KC, Meyer T, Watz H, Magnussen H: Physical activity is the strongest predictor of all-cause mortality in patients with COPD: a prospective cohort study. Chest 2011, 140:331-342.

11. Spruit MA, Singh SJ, Garvey C, ZuWallack R, Nici L, Rochester C, Hill K, Holland AE, Lareau SC, Man WD, Pitta F, Sewell L, Raskin J, Bourbeau J, Crouch R, Franssen FM, Casaburi R, Vercoulen JH, Vogiatzis I, Gosselink R, Clini EM, Effing TW, Maltais F, van der Palen J, Troosters T, Janssen DJ, Collins E, Garcia-Aymerich J, Brooks D, Fahy BF, et al: An official American Thoracic Society/European Respiratory Society statement: key concepts and advances in pulmonary rehabilitation. Am J Respir Crit Care Med 2013, 188:13-64.

12. Debigare $R$, Cote $C$, Maltais F: Peripheral muscle wasting in chronic obstructive pulmonary disease: Clinical relevance and mechanisms. Am J Respir Crit Care Med 2001, 164:1712-1717.

13. American Thoracic Society/European Respitaratory Society: Skeletal muscle dysfunction in chronic obstructive pulmonary disease. Am J Respir Crit Care Med 1999, 159:1-40.

14. Jobin J, Maltais F, Doyon JF, LeBlanc P, Simard PM, Simard AA, Simard C: Chronic obstructive pulmonary disease: capillarity and fiber-type characteristics of skeletal muscle. J Cardiopulm Rehabil 1998, 18:432-437.

15. Serres I, Hayot M, Prefaut C, Mercier J: Skeletal muscle abnormalities in patients with COPD: contribution to exercise intolerance. Med Sci Sports Exerc 1998, 30:1019-1027.

16. Ries AL, Bauldoff GS, Carlin BW, Casaburi R, Emery CF, Mahler DA, Make B, Rochester CL, Zuwallack R, Herrerias C: Pulmonary rehabilitation: Joint ACCP/AACVPR evidence-based clinical practice guidelines. Chest 2007, 131(5 Suppl):4S-42S

17. National Guideline Centre: Chronic obstructive pulmonary disease: management of chronic obstructive pulmonary disease in adults in primary and secondary care. London: Centre NCG; 2010.

18. Aliverti A, Macklem PT: The major limitation to exercise performance in COPD is inadequate energy supply to the respiratory and locomotor muscles. J Appl Physiol 2008, 105:749-751.

19. Debigare $\mathrm{R}$, Maltais $\mathrm{F}$ : The major limitation to exercise performance in COPD is lower limb muscle dysfunction. J Appl Physiol 2008, 105:751-753.

20. Wegner RE, Jorres RA, Kirsten DK, Magnussen H: Factor analysis of exercise capacity, dyspnoea ratings and lung function in patients with severe COPD. Eur Respir J 1994, 7:725-729.

21. American Thoracic Society/European Respiratory Society: Statement on pulmonary rehabilitation. Am J Respir Crit Care Med 2006, 173(12):1390-1413.

22. Killian KJ, Leblanc P, Martin DH, Summers E, Jones N, Campbell EJ: Exercise capacity and ventilatory, circulatory, and symptom limitation in patients with chronic aifflow limitation. Am Rev Respir Dis 1992, 156:935-940.

23. Walker PP, Burnett A, Flavahan PW, Calverley PM: Lower limb activity and its determinants in COPD. Thorax 2008, 63:683-689.

24. Mador MJ, Patel AN, Nadler J: Effects of pulmonary rehabilitation on activity levels in patients with chronic obstructive pulmonary disease. J Cardiopulm Rehabil Prev 2011, 31:52-59.

25. Waschki B, Spruit MA, Watz H, Albert PS, Shrikrishna D, Groenen M, Smith C, Man WD, Tal-Singer R, Edwards LD, Calverley PM, Magnussen H, Polkey MI, Wouters EF: Physical activity monitoring in COPD: compliance and associations with clinical characteristics in a multicenter study. Respir Med 2012, 106:522-530

26. Pitta F: Characteristics of physical activities in daily life in chronic obstructive pulmonary disease. Am J Respir Crit Care Med 2005, 171:972-977.

27. Shrikrishna D, Patel M, Tanner RJ, Seymour JM, Connolly BA, Puthucheary ZA, Walsh SL, Bloch SA, Sidhu PS, Hart N, Kemp PR, Moxham J, Polkey MI Hopkinson NS: Quadriceps wasting and physical inactivity in patients with COPD. Eur Respir J 2012, 40:1115-1122. 
28. Borges RC, Carvalho CR: Physical activity in daily life in Brazilian COPD patients during and after exacerbation. COPD 2012, 9:596-602.

29. Coronell C, Orozco-Levi M, Mendez R, Ramirez-Sarmiento A, Galdiz JB, Gea J: Relevance of assessing quadriceps endurance in patients with COPD. Eur Respir J 2004, 24:129-136

30. Serres I, Gautier V, Varray A, Prefaut C: Impaired skeletal muscle endurance related to physical inactivity and altered lung function in COPD patients. Chest 1998, 113:900-905.

31. Decramer M, Vestbo J, Bourbeau JC, Celli BR, Hui D, Varela MV, Nishimura M, Rodriguez Rosin R, Stockley RA, Vogelmeier C: Global strategy for the diagnosis, management, and prevention of COPD. 2014. http://www. goldcopd.org/guidelines-global-strategy-for-diagnosis-management.html.

32. Miller MR, Hankinson J, Brusasco V, Burgos F, Casaburi R, Coates A, Crapo R, Enright $P$, van der Grinten $C P$, Gustafsson P, Jensen R, Johnson DC, Maclntyre N, McKay R, Navajas D, Pedersen OF, Pellegrino R, Viegi G, Wanger J, ATS/ERS Task Force: Standardisation of spirometry. EurRespir J 2005, 26:319-338

33. Miller MR, Crapo R, Hankinson J, Brusasco V, Burgos F, Casaburi R, Coates A, Enright $P$, van der Grinten $C P$, Gustafsson $P$, Jensen $R$, Johnson DC Maclntyre N, McKay R, Navajas D, Pedersen OF, Pellegrino R, Viegi G, Wanger J, ATS/ERS Task Force: General considerations for lung function testing. Eur Respir J 2005, 26:153-161.

34. Society ATSER: ATS statement: guidelines for the six-minute walk test. Am J Respir Crit Care Med 2002, 166:111-117.

35. Guyatt GH, Pugsley SO, Sullivan MJ, Thompson PJ, Berman L, Jones NL, Fallen EL, Taylor DW: Effect of encouragement on walking test performance. Thorax 1984, 39:818-822.

36. Kroidl RF, Schwarz S, Lehnigk B: Kursbuch Spiroergometrie. Stuttgart: Georg Thieme Verlag; 2007

37. Kocks JW, Asijee GM, Tsiligianni IG, Kerstjens HA, van der Molen T: Functional status measurement in COPD: a review of available methods and their feasibility in primary care. Prim Care Respir J 2011, 20:269-275.

38. Dourado VZ, Antunes LC, Tanni SE, de Paiva SA, Padovani CR, Godoy I: Relationship of upper-limb and thoracic muscle strength to 6-min walk distance in COPD patients. Chest 2006, 129:551-557.

39. Patel SA, Benzo RP, Slivka WA, Sciurba FC: Activity monitoring and energy expenditure in COPD patients: a validation study. COPD 2007, 4:107-112

40. Hill K, Dolmage TE, Woon L, Goldstein R, Brooks D: Measurement properties of the SenseWear armband in adults with chronic obstructive pulmonary disease. Thorax 2010, 65:486-491.

41. Langer D, Gosselink R, Sena R, Burtin C, Decramer M, Troosters T: Validation of two activity monitors in patients with COPD. Thorax 2009, 64:641-642.

42. Swallow EB, Reyes D, Hopkinson NS, Man WDC, Porcher R, Cetti EJ, Moore AJ, Moxham J, Polkey MI: Quadriceps strength predicts mortality in patients with moderate to severe chronic obstructive pulmonary disease. Thorax 2007, 62:115-120

43. Gosselink R, Troosters T, Decramer M: Peripheral muscle weakness contributes to exercise limitation in COPD. Am J Respir Crit Care Med 1996, 153:976-980.

44. Maltais F, Leblanc P, Jobin J, Casaburi R: Peripheral muscle dysfunction in chronic obstructive pulmonary disease. COPD 2000, 21:665-677.

45. van Gestel AJ, Clarenbach CF, Stöwhas AC, Rossi VA, Sievi NA, Camen G, Russi EW, Kohler M: Predicting daily physical activity in patients with chronic obstructive pulmonary disease. PLoS One 2012, 7:e48081.

46. Pitta F, Troosters T, Probst VS, Langer D, Decramer M, Gosselink R: Are patients with COPD more active after pulmonary rehabilitation? Chest 2007, 134:273-280

doi:10.1186/2049-6958-9-37

Cite this article as: Rausch-Osthoff et al:: Association between peripheral muscle strength, exercise performance, and physical activity in daily life in patients with Chronic Obstructive Pulmonary Disease. Multidisciplinary Respiratory Medicine 2014 9:37.

\section{Submit your next manuscript to BioMed Central and take full advantage of:}

- Convenient online submission

- Thorough peer review

- No space constraints or color figure charges

- Immediate publication on acceptance

- Inclusion in PubMed, CAS, Scopus and Google Scholar

- Research which is freely available for redistribution

Submit your manuscript at www.biomedcentral.com/submit
C Biomed Central 